\title{
NEST RECOGNITION IN THE ANT, LEPTOTHORAX AMBIGUUS EMERY \\ (HYMENOPTERA: FORMICIDAE)*
}

\author{
By Thomas M. Alloway and Sandra Hodgson \\ Erindale College, University of Toronto, \\ Mississauga, Ontario L5L 1C6, Canada
}

\section{INTRODUCTION}

Leptothorax ambiguus Emery is a species of minute ants. In southern Ontario, colonies most frequently nest in old Quercus alba and Q. rubra acorns and in Carya ovata and C. cordiformis hickory nuts, which beetle larvae (especially Curculionidae) and other insects have partly hollowed out before the ants move in. L. ambiguus colonies frequently contain several functional queens (polygyny) and often occupy several acorn nests (polydomy). A 'typical' large colony would occupy 2 or 3 acorn nests and consist of 3 or 4 queens, 75 to 100 workers, and a brood of eggs, larvae, and pupae (Alloway et al. 1982).

L. ambiguus colonies defend the area around their nests against incursions by workers from other $L$. ambiguus colonies and from colonies of two closely related species, $L$. curvispinosus Mayr and $L$. longispinosus Roger. During territorial battles, workers bite and sting their adversaries and employ tandem running (Möglich et al. 1974) to recruit nestmates to places where workers from the other colony have been encountered (Alloway 1980). The co-occurrence of territoriality and polydomy and the fact that $L$. ambiguus colonies are sometimes raided by the slave-making parasites Leptothorax duloticus Wesson or Protomognathus americanus (Emery) led us to wonder whether $L$. ambiguus colonies possess the capacity to discriminate between one of their own nests and a nest belonging to another L. ambiguus colony. Such an ability should be useful if part of a polydomous colony had to evacuate a nest in which they had been living and emigrate to one of their colony's other nests as a consequence of either a territorial fight, a slave raid, or structural damage to their acorn nest.

*Manuscript received by the editor June 18, 1990. 


\section{EXPERIMENT 1}

\section{Materials AND Methods}

The purpose of Experiment 1 was to determine whether L. ambiguus colonies can distinguish an artificial nest containing a fragment of the acorn with which the colony had been living in nature from nests containing part of another colony's acorn or part of a previously uninhabited acorn. A total of 80 colonies were involved in the study. At least one week before testing, the colonies, which had been collected during the fall of 1987 in Mississauga, Ontario, and then vernalized (Hare \& Alloway 1987), were placed in artificial nests (Alloway 1979) and cultured at $22^{\circ} \mathrm{C} \pm 2^{\circ}$ in $15 \times 150 \mathrm{~mm}$ plastic petri dishes which also contained a cotton-stoppered water vial and food (Bhatkar \& Whitcomb 1970). Approximately one third of the colony's original acorn nest was placed inside its artificial nest. Forty pairs of colonies were then formed by matching them as closely as possible on the basis of the number of workers. On the morning of the testing day, both colonies in a pair were placed in clean artifical nests which did not contain an acorn fragment; and the acorn fragments with which the ants had been living were placed in clean, empty nests. Painstaking vigilance was exercised to ensure that all adults and brood were removed from the acorn fragments with which the ants had been living. The acorn fragments were examined under a dissecting microscope and, when necessary, broken into smaller pieces to insure that no adult or immature ants were overlooked.

One of the colonies in the pair was then selected at random for testing. Testing took place in square plexiglass arenas measuring $45 \mathrm{~cm}$ on each side. Three artificial nests containing acorn fragments were arrayed in a straight line approximately $10 \mathrm{~cm}$ in front of the centre of one wall of the arena and with a distance of $4.5 \mathrm{~cm}$ between the nests. One nest contained the acorn fragment(s) with which the test colony had been living, one nest contained the acorn fragment(s) with which the other colony in the pair had been living, and the third nest contained a fragment of an acorn previously uninhabited by ants. The left-to-right positioning of nests containing the three kinds of acorn fragments varied randomly for different replicates of the experiment. At the beginning of the test, the nest containing the test colony was placed $14 \mathrm{~cm}$ in front of the centre nest in the array; and the nest lid was removed to elicit emigration. 
A choice was scored if the test colony moved completely into one of the choice nests within $5 \mathrm{~h}$; otherwise the trial was scored as inconclusive.

\section{RESULTS}

Twenty colonies moved into the acorn nest containing fragment(s) of their own acorn, 7 colonies moved into the nest containing fragment(s) of the acorn previously inhabited by the other colony in the pair, 5 colonies moved into the nest containing the previously uninhabited acorn fragment, and 8 replicates were inconclusive, i.e. the colony either failed to move or moved into more than one nest. A chi-square analysis from which the inconclusive replicates were excluded revealed that the choices were not random $\left(\chi^{2}=12.44, \mathrm{df}=2 \mathrm{p}=0.002\right)$; and we conclude that the test colonies chose the nest containing their own acorn at a rate significantly greater than chance.

\section{EXPERIMENT 2}

Experiment 1 demonstrated that colonies choose a nest containing a fragment of their own acorn at a rate higher than chance, but it did not determine whether the choice was based on differences between the acorns or on a colony-specific mark which the ants apply to the acorns which they inhabit. Experiment 2 was designed to distinguish between these two alternatives.

\section{Materials ANd Methods}

Colonies were collected and vernalized as in Experiment 1. Two large fragments which were as nearly identical as we could make them were obtained from each of 42 previously uninhabited $Q$. rubra and $Q$. alba acorns and placed in clean artificial nests; and 42 pairs of L. ambiguus colonies, which had been formed by matching worker populations as closely as possible, were set up in the nests containing the paired acorn fragments. After both colonies in a colony pair had lived with the acorn fragments for a least a week, we employed the same precautions described in connection with Experiment 1 to remove the ants from the acorn fragments with which they had been living. One colony in each pair was then selected at random and tested as in Experiment 1, except that only a two-choice situation was employed in the present study. The choices offered were between a clean artificial nest containing the acorn 
fragment with which the test colony had been living and an identical nest containing the fragment of the same acorn with which the other colony in the pair had been living.

\section{Results}

Twenty-seven test colonies chose the nest containing the acorn fragment with which they had been living, 10 colonies chose the nest containing the fragment of the same acorn with which the other colony had been living, and 5 colonies made no definitive choice within the 5-h choice period. A chi-square test from which the inconclusive replicates were excluded revealed that the choices were nonrandom $\left(\chi^{2}=7.81, \mathrm{df}=1, \mathrm{p}=0.005\right)$; and we conclude that the colonies moved into the nest containing the acorn fragment with which they had previously been living at a greater-than-chance rate. Since in this experiment both nests contained fragments of the same acorn, it seems most likely that the choice was based on some colony-specific mark laid down by the ants themselves.

\section{Discussion}

The present study shows that $L$. ambiguus colonies are able to recognize and return to nests containing acorn fragments with which the colony has recently been living at a greater-than-chance rate. These findings indicate that $L$. ambiguus colonies can recognize their nesting material. Quite probably this recognition is based upon chemical cues which the ants deposit on the nesting material. The likely involvement of chemical cues is suggested by the facts (a) that chemical cues are involved in nestmate (Stuart 1987, 1988) and brood recognition (Hare \& Alloway 1987; Alloway \& Hare in press) in Leptothorax colonies, (b) that the harvester ant Pogonomyrmex badius chemically marks the soil in which it nests (Hangartner, Reichson, \& Wilson 1970), and (c) that several ant species lay down chemical cues to mark the foraging territories around their nests (Cammaerts, Morgan \& Tyler 1977; Haskins \& Haskins 1983; Hölldobler \& Wilson 1977; Jaffe \& Puche 1984). However, further work is needed to establish the nature of the recognition cue more definitively. In particular, we need to discover whether the 'colony odor' which the workers bear on the surface of their bodies (Stuart $1987,1988)$ simply rubs off and marks the nest incidentally or whether some special nest-marking process is involved. 


\section{SUMMARY}

The capacity of Leptothorax ambiguus Mayr colonies to recognize their nesting material was determined in two experiments. In the first study, colonies reliably discriminated an artificial nest containing a fragment of the acorn nest in which the colony had been living in nature from nests containing an acorn fragment from another colony's nest or a fragment of a previously uninhabited acorn. In the second experiment, colonies reliably discriminated a nest containing a fragment of acorn with which they had been living in the laboratory from a nest containing a fragment of the same acorn with which another colony had been living. These results indicate that $L$. ambiguus colonies recognize their acorn nests. The recognition is probably based on a chemical mark.

\section{ACKNOWLEDGEMENTS}

This research was supported by a grant to TMA from the Natural Sciences and Engineering Research Council (Canada). The data reported here were collected in partial fulfilment of the requirements for SH's B.Sc. thesis. We thank Akhilesh Leighl for his technical assistance.

\section{REFERENCES}

Alloway, T. M. (1979) Raiding behaviour of two species of slave-making ants, Harpagoxenus americanus (Emery) and Leptothorax duloticus Wesson (Hymenoptera: Formicidae). Animal Behaviour, 27: 202-210.

Alloway, T. M. (1980) The origins of slavery in leptothoracine ants (Hymenoptera: Formicidae). American Naturalist, 115: 247-261.

Alloway, T. M., Buschinger, A., Talbot, M., Stuart, R. \& Thomas, C. (1982) Polygyny and polydomy in three North American species of the ant genus Leptothorax Mayr. Psyche, 89: 249-274.

Alloway, T. M., \& Hare, J. F. (In press) Experience-independent attraction to slave-maker ant larvae in host-species ant workers (Leptothorax longispinosus; Hymenoptera: Formicidae). Behaviour.

Cammaerts, M.-C., Morgan, E.-R., \& Tyler, R. (1977) Territorial marking in the ant Myrmica rubra L. (Formicidae). Biology of Behaviour, 2: 263-272.

Hangartner, W., Reichson, J. M., \& Wilson, E. O. (1970) Orientation to nest material by the ant, Pogonomyrmex badius (Latreille). Animal Behaviour, 18: 331-334.

HARe, J. F. \& Alloway, T. M. (1987) Early learning and brood discrimination in leptothoracine ants (Hymenoptera: Formicidae). Animal Behaviour, 35: 1720-1724. 
Haskins, C. P., \& Haskins, E. F. (1983) Situation and location-specific cues in the compatibility response in Rhitidoponera metallica (Hymenoptera: Formicidae: Ponerinae). Psyche, 90: 163-174.

Hölldobler, B., \& Wilson, E. O. (1977). Colony-specific territorial pheromone in the African weaver ant Oecophylla longinoda (Latreille). Proceedings of the National Academy of Science (U.S.A.), 74: 2072-2075.

JAFFe, K., \& PUCHE, H. (1984) Colony-specific territorial marking with the metapleural gland secretion in the ant Solenopsis geminata (Fabr). Journal of Insect Physiology, 30: 265-270.

Möglich, M., Maschwitz, U., \& Hölldoobler, B. (1974) Tandem calling: A new kind of signal in ant communication. Science, 172: 1046-1047.

STUART, R. J. (1987) Individual workers produce colony-specific nestmate recognition cues in the ant, Leptothorax curvispinosus. Animal Behaviour, 35: 1062-1969.

StUART, R. J. (1988) Collective cues as a basis for nestmate recognition in polygynous leptothoracine ants. Proceedings of the National Academy of Science (USA), 85: 4572-4575. 

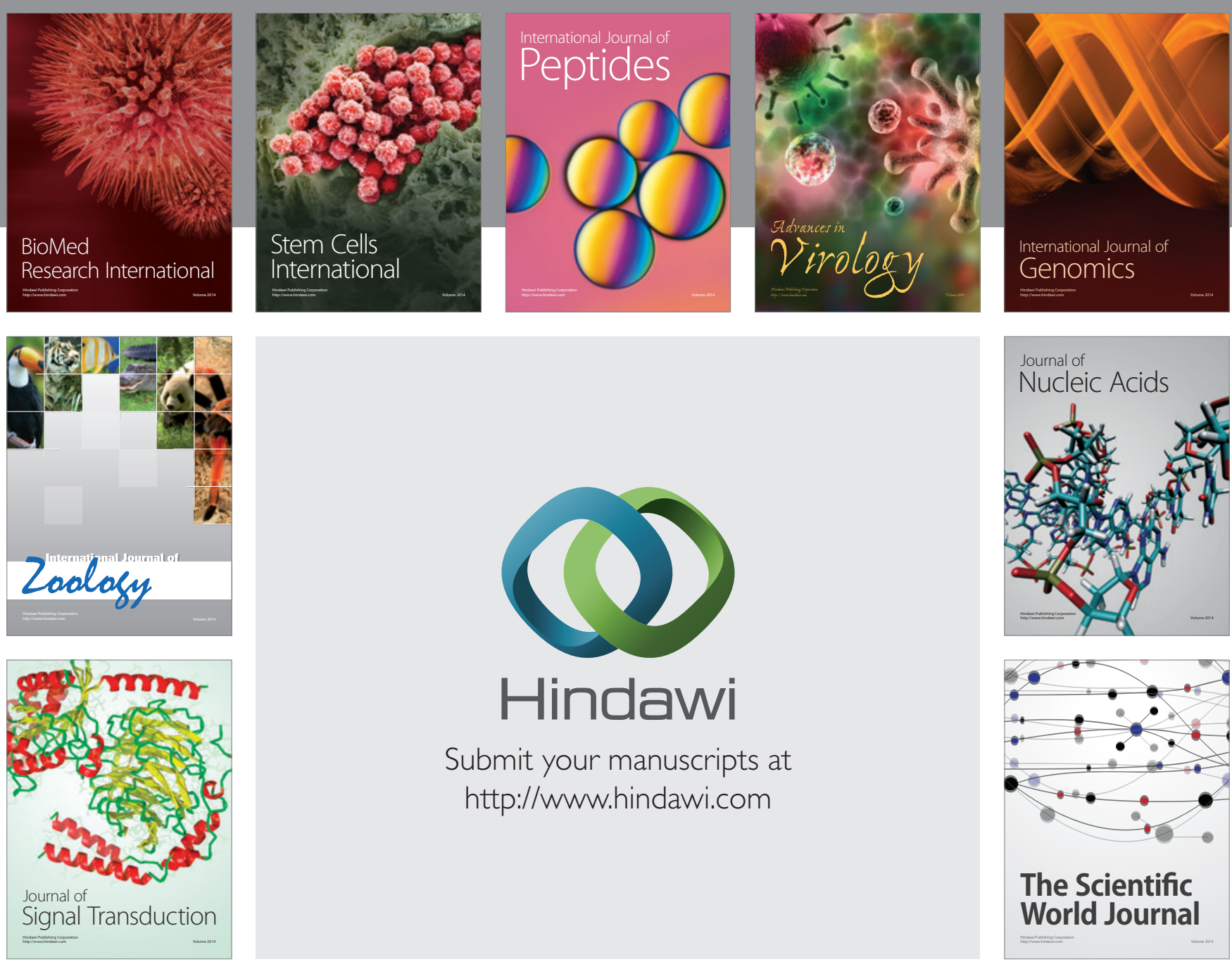

Submit your manuscripts at

http://www.hindawi.com
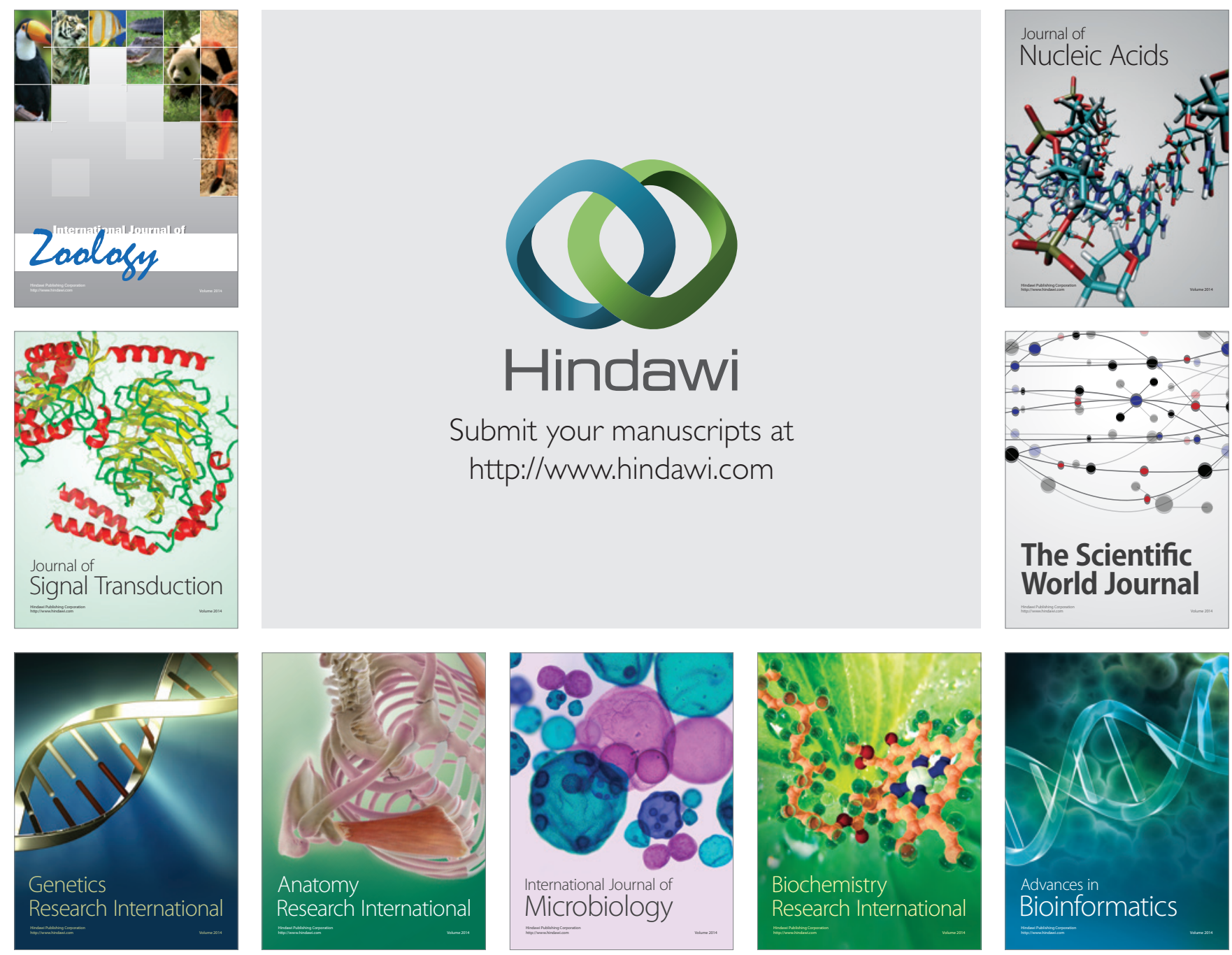

The Scientific World Journal
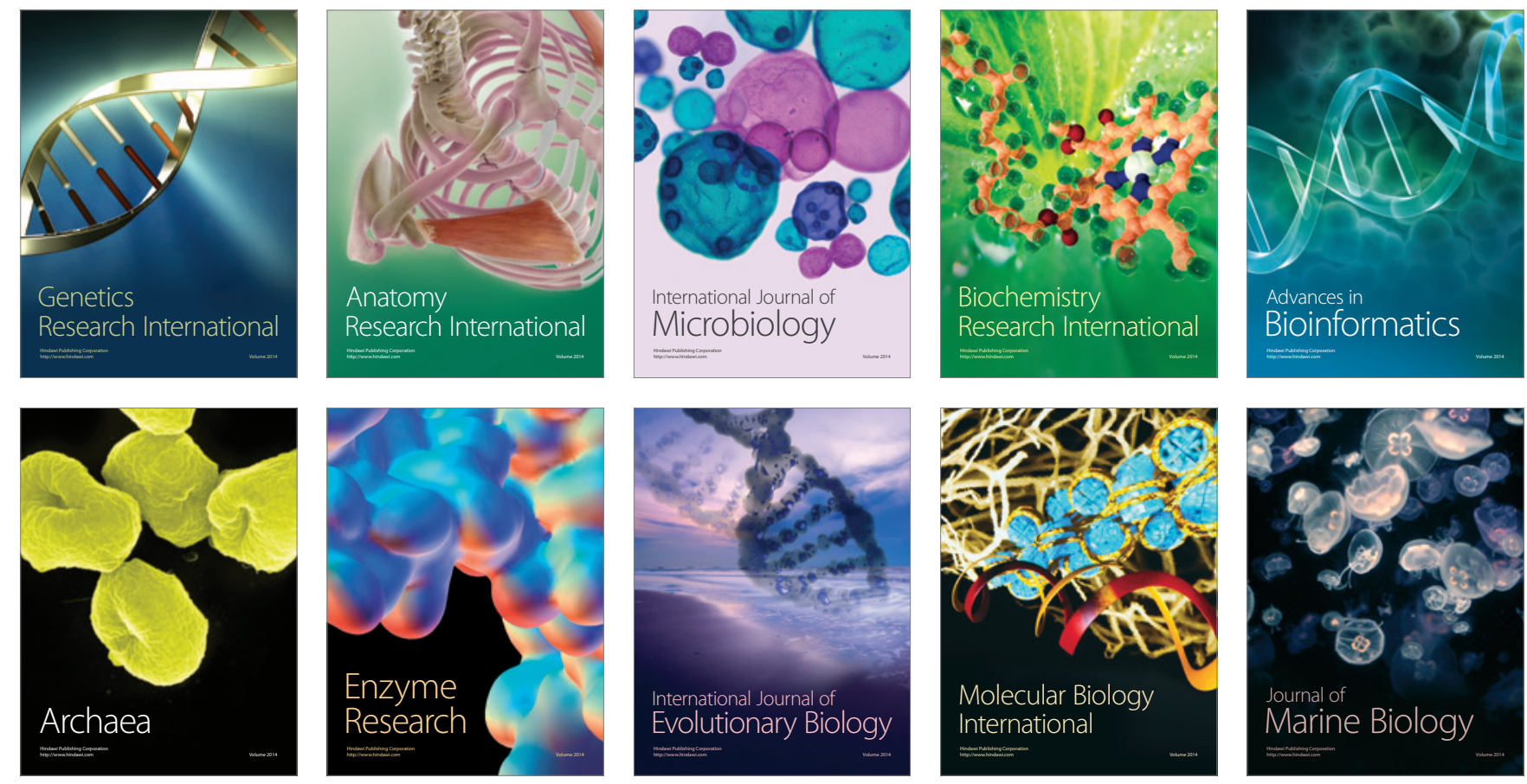